\title{
Screening of lovastatin (HMG-CoA reductase inhibitor) from edible wild mushrooms
}

\section{Pushpa $\mathbf{H}^{1^{*}}$, Priyata $\mathbf{H}^{1}$, Nomita Devi $\mathrm{K}^{1}$, Onya $\mathbf{N}^{1}$, Vijayalakshmi $\mathrm{A}^{1}$ and Ramesh $\mathrm{DH}^{2}$}

\footnotetext{
${ }^{1 *}$ Department of Microbiology, M.S.Ramaiah College of Arts, Science and Commerce, Bangalore.

${ }^{2}$ Public Health Institute, Department of Health and Family Welfare, Government of Karnataka, Bangalore.
}

Pushpa H, Priyata H, Nomita Devi K, Onya N, Vijayalakshmi A, Ramesh DH. 2016 - Screening of lovastatin (HMG-CoA reductase inhibitor) from edible wild mushrooms. Current Research in Environmental \& Applied Mycology 6(3), 190-196, Doi 10.5943/cream/6/3/6

\begin{abstract}
The aim of this research was to extract and analyse lovastatin from edible wild mushrooms. Lovastatin is an inhibitor of 3-hydroxy-3-methylglutaryl coenzyme-A reductase (HMG-CoA reductase) enzyme and a competitive inhibitor of the biosynthesis of cholesterol. Seven wild edible mushrooms species were analysed for the production of lovastatin. Bioassays, TLC and UV spectral analysis confirmed that six of the edible wild mushrooms were lovastatin producers, which showed zones of inhibition against Candida albicans, similar Rf values as that of standard and $\lambda_{\max }$ at $238 \mathrm{~nm}$. The production of lovastatin was also confirmed by high performance liquid chromatography (HPLC). Schizophyllum commune produced the highest concentration of lovastatin and its occurrence in the mushroom is reported for the first time. This mushroom can also serve as a potential species for genetic engineering and strain improvement studies to enhance the yield of lovastatin. Hence this property of mushrooms could be exploited in food and pharmaceutical industries.
\end{abstract}

Key words - bioassay - HPLC - Schizophyllum commune - TLC - UV spectral analysis

\section{Introduction}

The World Health Organization estimated that 17.3 million lives were lost in 2008 and an expected 23.6 million people will die of cardiovascular diseases by the year 2030 (WHO, 2011). About $80 \%$ of mortality rates were reported from the lower and middle income countries. The treatment of hypercholesterolemia is targeted by decreasing the low density lipoprotein by medications. A wide variety of biological active compounds are produced by fungi (De Silva et al. 2012a, 2012b, 2013) including statins (anti-cholesterol compounds). Lovastatin is an interesting fungal metabolite. It functions as a competitive inhibitor of the enzyme, 3-hydroxy-3methyl-glutaryl enzyme in cholesterol biosynthesis. HMG Co-A reductase is an important enzyme in the process of converting HMG CoA to mevalonate. HMG CoA reductase is associated with lovastatin at higher concentrations, than HMG $\mathrm{CoA}$, and as a result, it acts as a competitive inhibitor with the substrate and blocks the production of mevalonate and then inhibits the cholesterol biosynthesis (Tobert et al. 2003). Hence, lovastatin is used as an effective drug for the treatment of hypercholesterolemia. Of many statin molecules, lovastatin and mevastatin are natural, while other statins like rosuvastatin, simvastatin, pravastatin, fluvastatin, atrovastin, cerivasatin, are produced semi-synthetically from lovastatin (Jonathan 2003). Many of the 
soil dwelling fungi such as Aspergillus, Gymnoascus, Hypomyces, Monascus, Paecilomyces, Penicillium, Phoma, Phythium, Pleurotus, Scopolariopsis, and Trichoderma are reported as lovastatin producers (Szakacs 1998, Manzoni 1999, Manzoni 2002, Bizukojc \& Stanislaw 2009, Cabral et al. 2010).

The main objective of the present study was to discover new producers of lovastatin in edible mushrooms by rapid screening of lovastatin by Candida albicans bioassay method, TLC and UV spectral analysis, which are simple and sensitive and can also be confirmed through HPLC.

\section{Materials \& Methods}

\section{Collection of mushrooms}

Basidiocarps of wild mushrooms were collected from different regions of Bangalore, Karnataka and from Manipur during the monsoon season June-September (2014), Singer (1975) and Arora et al. (1986) classification was used to identify the mushrooms belonging to the subdivision Basidiomycotina. Seven mushrooms were collected and identified and three species belonged to the order Aphylloporales (Pleurotus ostreatus, Schizophyllum commune, Ganoderma applanatum), three species to the order Agaricales (Tricholoma giganteum, Calocybe indica, Agaricus campestris); and one species belonging to the order Tremellales - jelly fungi (Auricularia auricula) (Fig. 1). Pure cultures of mushrooms were isolated as suggested by Pushpa et al. (2014). The mushrooms were placed at $40-45^{\circ} \mathrm{C}$ in a hot air oven for the process of complete dehydration and preserved in an air tight container for further studies.

\section{Extraction of lovastatin}

The extraction of lovastatin was done as explained by Siamak et al. (2003). The dried basidiocarps were made in to fine powder and homogenized with ethyl and acidified to $\mathrm{pH} 3$ by using $\mathrm{HCl}$. The extract was taken in the Eppendorf tube and kept in the rotary shaker at $260 \mathrm{rpm}$ for 2 hours at $28^{\circ} \mathrm{C}$. After that it was again centrifuged at $10000 \mathrm{rpm}$ for 5 minutes the supernatant was collected and used for further studies.

\section{Screening of lovastatin}

\section{Bioassay of HMG CoA reductase inhibitor using Candida albicans}

The method for screening lovastatin producing isolates was adopted as suggested by Prabhakar et al. (2011), briefly potato dextrose agar was prepared and poured into sterile Petri dish in aseptic conditions and the media was allowed to solidify. Using a cork borer, wells were aseptically made on the surface of the solidified media and 24 hours old broth culture of Candida albicans was swabbed on to the surface of the media. The extract of different isolates was loaded into the well, ethyl acetate was used as negative control and standard lovastatin was used as the positive control. All the inoculated plates in triplicates were incubated at $28-30^{\circ} \mathrm{C}$ for $24-48$ hours and observed for the zone of inhibition.

\section{Analysis of lovastatin using thin layer chromatography (TLC)}

TLC was used to analyse the presence of lovastatin in the extracted samples as suggested by Samiee (2003), Siamak (2003) and Atalla et al. (2008). All extracts and the standard were spotted on the silica plate. The mobile phase was dichloromethane: ethyl acetate in the ratio of 70:30 v/v. All the plates were observed under UV radiation at $254 \mathrm{~nm}$. For further convenience and analysis, the bands were stained with iodine vapor and $\mathrm{Rf}$ values was calculated and compared with that of standard lovastatin.

\section{UV spectrometric analysis of lovastatin}

The bands which show the $\mathrm{Rf}$ values similar to that of standard lovastatin were scrapped off and eluted with $1 \mathrm{ml}$ of acetonitrile solvent and filtered. The $\lambda$ max of the samples was determined at 238 $\mathrm{nm}$ using UV-Vis spectrophotometer. Further, the optical density of the sample was measured at 238 
$\mathrm{nm}$ and the concentration of the lovastatin was calculated using the standard graph of lovastatin (Lingappa et al. 2004).

\section{Confirmation of lovastatin using high performance liquid chromatography (HPLC)}

The extracted lovastatin was dissolved in $1 \mathrm{ml}$ of acetonitrile and $0.1 \mathrm{ml}$ of $0.1 \%$ of phosphoric acid incubated for 30 minutes and centrifuged at $1500 \mathrm{rpm}$ for 10 minutes. The supernatant was injected in the HPLC column C-18 $(250 \times 46 \mathrm{~cm})$ was added with eluent acetonitrile and phosphate acid 60:40 (v/v), the eluent rate was $1.5 \mathrm{ml} /$ minute, detector ultraviolet (UV) at $238 \mathrm{~nm}$ and the temperature of the column was $30^{\circ} \mathrm{C}$ (Samiee et al. 2003).

\section{Results \& Discussion}

\section{Screening of lovastatin extracted from different fungal isolates}

\section{Bioassay of lovastatin by well method using Candida albicans}

The screening of potential lovastatin producing mushrooms was carried out by measuring the zone of inhibition around the well, where the extracted lovastatin sample was loaded. The diam. of zone of inhibition ranged from 2-2.8 cm (Table 1) and Fig 1. Tricholoma giganteum produced a maximum zone of inhibition. The difference in clear zones may be due to the variation of physiology and genetic characteristics of the specimens, ability of the lovastatin to diffuse in the agar, and incubation period (Vilches Ferrón et al. 2005). The mechanism of sensitivity towards lovastatin is that lovastatin in ethyl acetate extract is in the form of $\beta$-hydroxy acid, which is an antifungal agent. The cell membrane of $C$. albicans contains a lipid bilayer. The composition of the cell wall comprises sterols, which is the target of antifungal activity, the enzyme that is involved in the cell wall synthesis. The mechanism of anti-yeast inhibition was mycosin contact directly with the sterol in the cell membrane, causing leaks in the membrane and the loss of the intracellular component, mycosin attaches to RNA and inhibits the protein synthesis, while mycosin inhibits ergosterol synthesis, causing the increase of membrane permeability and the damage of the membrane (Ganiswara et al. 1985).

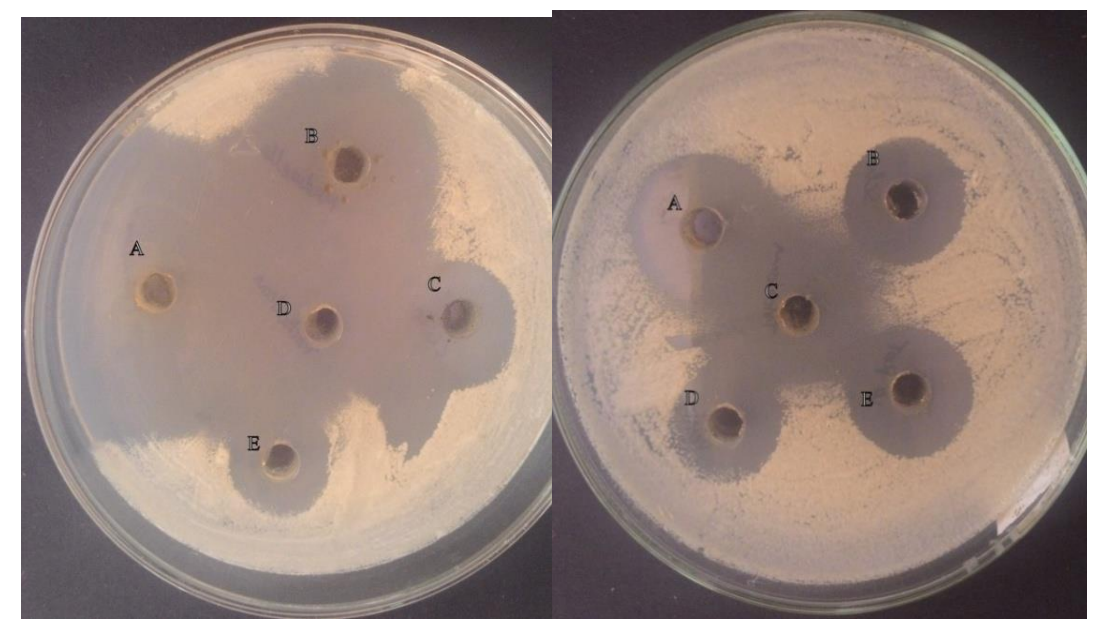

Fig. 1 - Plates showing zone of inhibition against Candida albicans.

\section{Rapid confirmation of lovastatin by thin layer chromatography}

To ensue whether the zone of inhibition exhibited by different isolates in bioassays were due to lovastatin activity, an ethyl acetate extract from different isolates were subjected to TLC for rapid confirmation (Fig. 2). Six of the seven isolates produced an Rf similar as that of standard lovastatin. TLC confirmed that the inhibition of growth of $C$. albicans in the bioassay was due to the lovastatin. Our results concur with those of Lingappa (2004), Prabhakar \& Lingappa (2011), Mangunwardoyo et al. (2012), Chaynika (2014) and Dhar et al. (2015). 
Table 1 Bioassay of lovastatin by well method using Candida albicans

\begin{tabular}{lll}
\hline SI & Mushrooms & Zone of inhibition in CM \\
No. & \\
\hline 01 & Tricholoma giganteum & $2.8 \pm 0.22$ \\
02 & Agaricus campestris & $2.7 \pm 0.13$ \\
03 & Schizophyllum commune & $2.4 \pm 0.24$ \\
04 & Auricularia auricular & $2.5 \pm 0.58$ \\
05 & Calocybe indica & $2 \pm 0.10$ \\
06 & Ganoderma applanatum & $2.1 \pm 0.23$ \\
07 & Pleurotus ostreatus & $2.1 \pm 0.21$ \\
\hline
\end{tabular}

\section{Determination of lovastatin by UV analysis}

Quantitative estimation of lovastatin was carried out for different isolates using a UV-Vis spectrophotometer. The spectral studies of standard lovastatin revealed a maximum absorption peak $(\lambda$ $\max )$ at $238 \mathrm{~nm}$. The results observed under these studies were in good agreement with the data published in Merck Index (Lingappa et al. 2004). Therefore, $238 \mathrm{~nm}$ was considered as the constant for all the culture samples to measure the OD for lovastatin. The absorbance of the different concentration of standard lovastatin ranging from $10-100 \mu \mathrm{g} / \mathrm{ml}$ was measured and a standard graph was prepared to obtain a linear curve. The OD of different mushroom lovastatin extract was plotted on the standard graph to obtain the concentration of the lovastatin produced in each of the sample. The concentration of lovastatin in mushrooms ranged from $17-38 \mu \mathrm{g} / \mathrm{ml}$ respectively Schizophyllum commune and Pleurotus ostreatus produced the highest concentrations, viz $38 \mu \mathrm{g} / \mathrm{ml}$ and $30 \mu \mathrm{g} / \mathrm{ml}$ respectively. Agaricus campestris, Auricularia auricular, Calocybe indica, Ganoderma applanatum and Tricholoma giganteum also produced lovastatin. The presence of lovastatin in Pleurotus has been reported by Gunde et al. (1973) and Alarcón et al. (2003). However the presence of lovastatin in Schizophyllum commune and Tricholoma giganteum is reported for the first time.

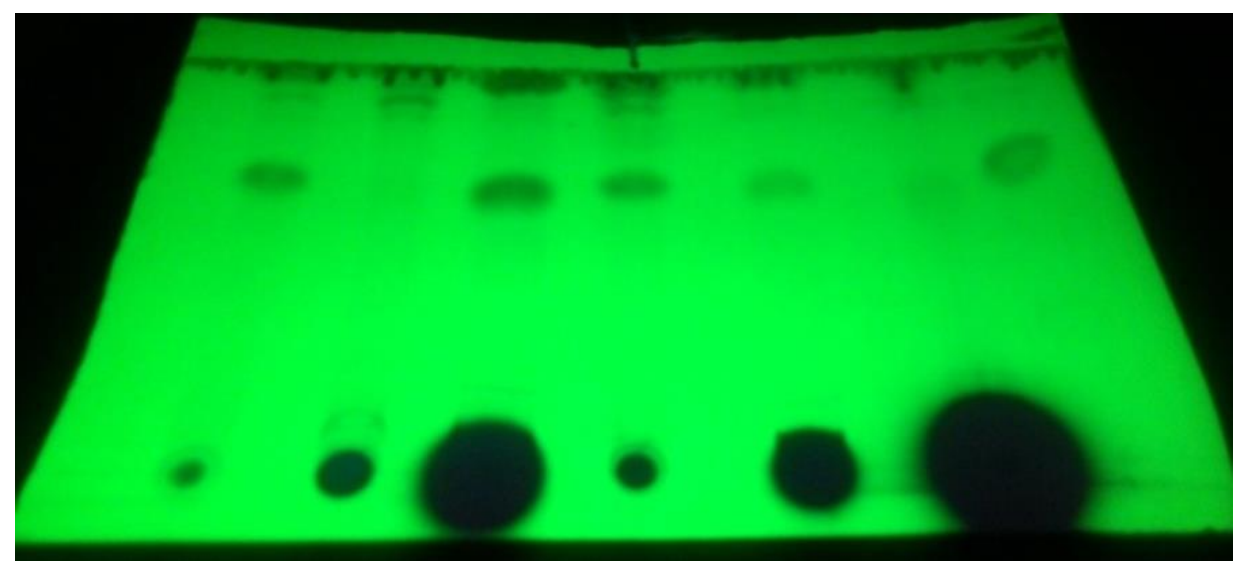

Fig. 2 - Rapid confirmation of lovastatin producing filamentous isolates by TLC method spots on TLC plates under UV source at $254 \mathrm{~nm}$

\section{HPLC analysis}

The extracts of lovastain from different isolates were subjected to HPLC analysis to confirm the amount of lovastatin produced. Chromatogram analysis indicated the peak of lovastatin standard with the retention time of 12.45 minutes (Fig. 3). The extracts of the fungal samples were eluted at a retention time of 12.770 minutes for Tricholoma giganteum and 12.450 mins for Schizophyllum commune (Fig. 4), which were much similar to the retention time obtained from the standard. It was also confirmed form HPLC analysis that the concentration of lovastatin in Schizophyllum commune was $43.3 \mathrm{ppm}$, and Tricholoma giganteum $0.52 \mathrm{ppm}$. Hence, from this investigation it was concluded that rapid method of determination of lovastatin can also be employed to screen lovastatin producing fungal isolates. HPLC confirmed that the production of lovastatin in Schizophyllum commune an edible 
wild mushroom which has the highest potential for the production of lovastatin, hence this mushroom could be cultivated and can be used as a food source and exploited commercially for the production of lovastatin. The presence of lovastatin in the mushroom Pleurotus ostreatus, P. saca and P. sapidus was confirmed by Cimerman (2006) and Radha \& Lakshmanan (2013).

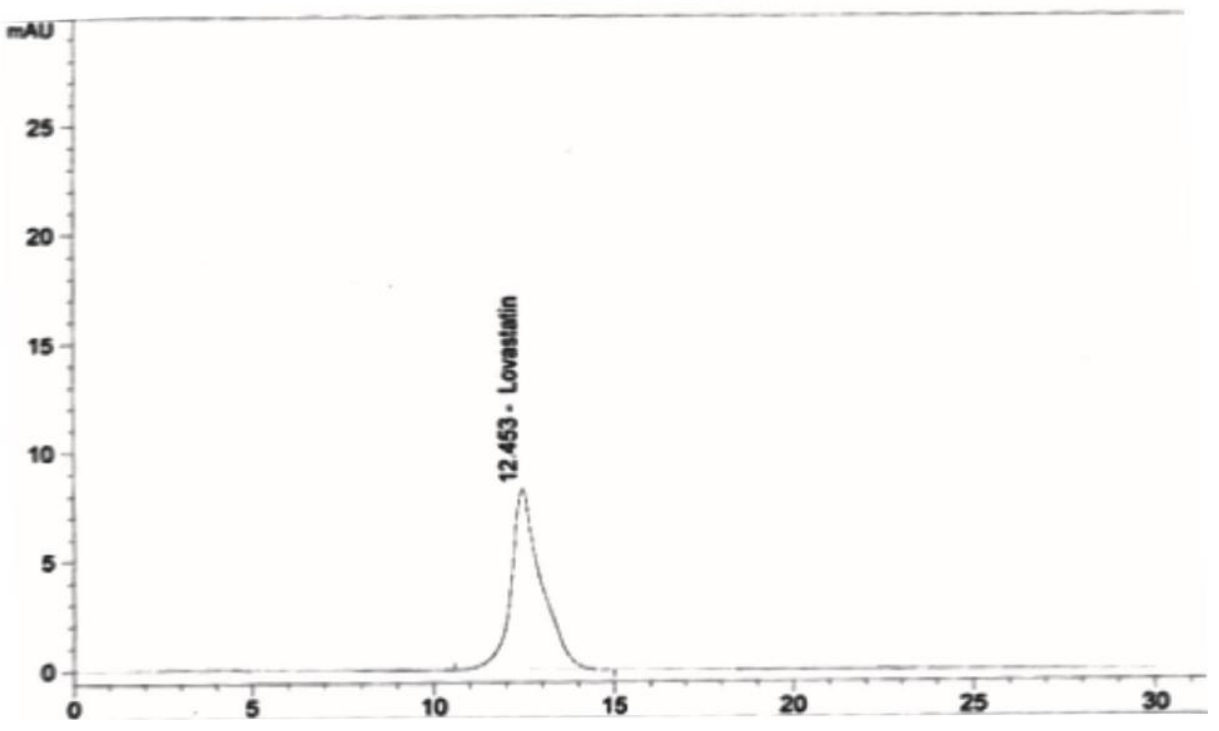

Fig. 3 - HPLC of standard lovastatin

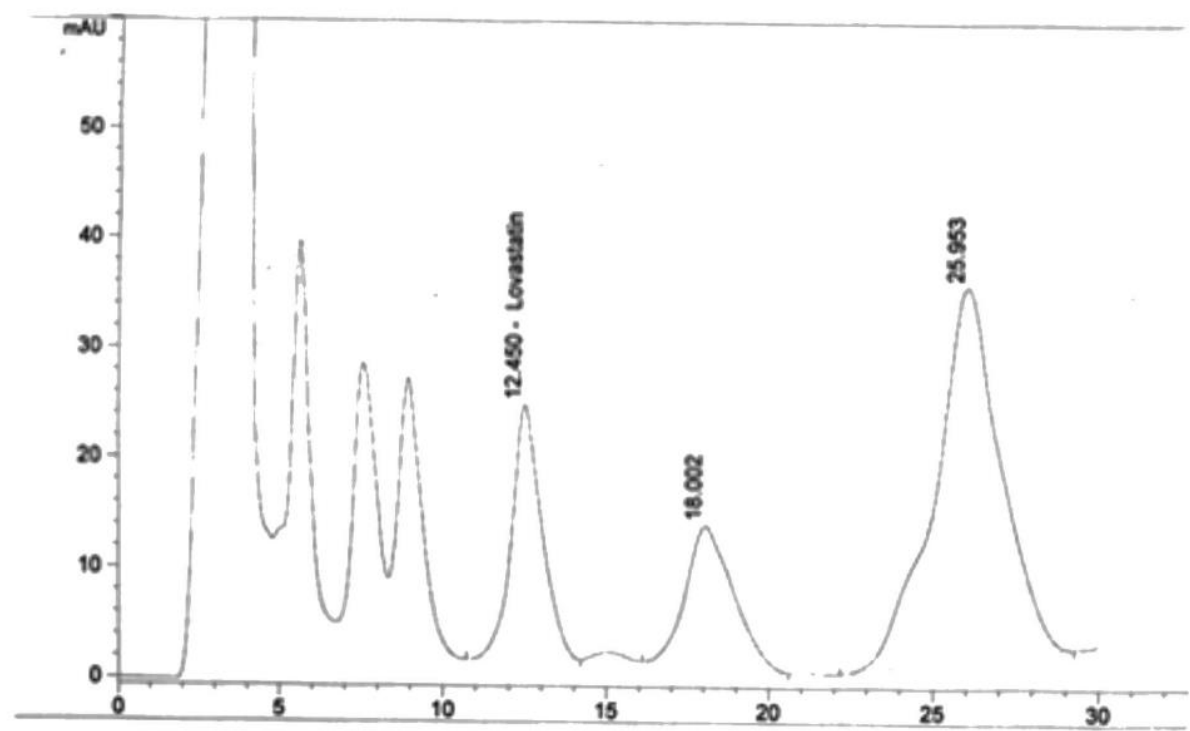

Fig. 4 - HPLC of lovastatin from the Schizophyllum commune extract.

\section{Acknowledgements}

We would like to thank the management of Gokula Education Foundation for all the support they have rendered to complete this research project.

\section{References}

Alarcón J, Águila S, Arancibia-Avila P, Fuentes O, Zamorano-Ponce E, Hernández M. 2003 Production and purification of statins from Pleurotus ostreatus (Basidiomycetes) strains. Zeitschrift für Naturforschung 58c, 62-64. 
Arora D. 1986 - Mushrooms Demystified. $2^{\text {nd }}$ edition, Ten Speed Press Berkeley, 959.

Atalla MM, Hamed ER, El-Shami AR. 2008 - Optimization of a culture medium for increased mevinolin production by Aspergillus terrus strain. Malaysian Journal of Microbiology 4(2), 610.

Bizukojc M, Stanislaw L. 2009 - Physiological, morphological and kinetic aspects of lovastatin biosynthesis by Aspergillus terreus. Biotechnology Journal 4(5), 1-61.

Cabral ME, Delgado OD, Sampietro DA, Catalan, Figueroa LIC, Farina JI. 2010 - Antifungal activity and the potential correlation with statin producing ability: an optimized screening applied to filamentous fungi from Las Yungas subtropical rainforest. Research Journal of Microbiology 5(9), 833-848.

Chaynika P, Srividya S. 2014 - Bioprospecting of lovastatin producing fungi isolating from soil samples. International Research Journal of Biological Sciences 3(9), 42-46.

Cimerman NG, Friedrich J, Cimerman A, Benicki N. 2006 - Screening fungi for the production of an inhibitor of HMG Co-A reductase: production of mevinolin by fungi of the genus Pleurotus. The Federation of European Microbiological Society Microbiology Letters 11(2-3), 203-206.

De Silva DD, Rapior S, Fons F, Bahkali AH, Hyde KD. 2012b - Medicinal mushrooms in supportive cancer therapies: an approach to anti-cancer effects and putative mechanisms of action Fungal Diversity 55, 1-35.

De Silva DD, Rapior S, Sudarman E, Stadler M, Xu J, Aisyah S, Hyde KD. 2013 - Bioactive metabolites from macrofungi: ethnopharmacology, biological activities and chemistry Fungal Diversity 62, 1-40.

De Silva DD, Rapiora S, Hyde KD, Bahkali AH, 2012a-Medicinal mushrooms in prevention and control of diabetes mellitus. Fungal Diversity 56, 1-29.

Dhar R, Choudhury GB, Nigam VK. 2015 - Screening of different fungi for the production of lovastatin. Asian Journal of Biomedical and Pharmaceutical Sciences 5(44), 24-29.

Ganiswara SG, Rianto S, Frans DS, Purwantyastuti Farmakoligi dan Tearpi. Edisi V. Jakarta. 1985 Bagain Farmakologi Kedpkteram UI 10, 643.

Gunde CN, Friedrich J, Cimerman A, Benicki N. 1973 - Screening fungi for the production of an inhibitor of HMG CoA reductase: production of mevinolin by the fungi of the genus Pleurotus, The Federation of European Microbiological Society Microbiology Letters 111, 203-206.

Jonathan AT. 2003- Lovastatin and beyond: the history of the HMG-CoA reductase inhibitors. Nature Review 2, 517-526.

Lingappa K, Vivek Babu CS, Siddalingeshwar K, Pramod T. 2004 - Isolation, screening and rapid confirmation of lovastatin producing strains of Aspergillus terreus. Indian Journal of Microbiology 44(2), 133-135.

Mangunwardoyo W, Rafliyanti Y, Kusmana D. 2012 - Bioprospect of lovastatin in Aspergillus spp. from University of Indonesia Culture Collection (UICC). World Applied Sciences Journal 16(2), 183-188.

Manzoni M, Bergomi S, Rollini M, Cavazzoni V. 1999 - Production of statins by filamentous fungi. Biotechnology Letters 21, 253-257.

Manzoni M, Rollini M. 2002 - Biosynthesis and biotechnological production of statins by filamentous fungi and application of these cholesterol lowering drugs. Applied Microbiology and Biotechnology 58, 555-564.

Prabhakar M, Lingappa K, Vivek B, Amena S, Vishalakshi N, Mahesh D. 2011 - Characterization of physical factors for the optimum lovastatin production by Aspergillus terreus klvbmu21 under solid state fermentation. Journal of Recent Advances in Applied Sciences 27, 1-5.

Prabhakar M, Lingappa K. 2011 - Screening of Aspergillus terreus Klvb28 mutants by bioassay method for the overproduction of lovastatin (A vital statin in coronary heart disease). Research Journal of Biotechnology 6(3), 33-35.

Pushpa H, Anand M, Kashimaiah P and Penugonda JVPradeep. 2014 - Ganoderma applanatum (Persoon) Patouillard as a source of anticancer and antioxidant agent. International Journal of Pharma and Biosciences 5(2), 276-282. 
Radha KV, Lakshmanan D. 2013 - A review: lovastatin production and application. Asian Journal of Pharmaceutical and Clinical Research 6(3), 21-26.

Samiee SM, Moazami N, Haghighi S, Aziz MF, Mirdamadi S and Reza BM. 2003 - Screening of lovastatin production by filamentous fungi. Iranian Biomedical Journal 7(1), 29-33.

Singer R. 1975 - The Agaricales in modern taxonomy. $3^{\text {rd }}$ edition. Vaduz, J. Cramer.

Szakacs G, Morovjan G, Tengrendy PR. 1998 - Production of lovastatin from a wild strain of Aspergillus terreus. Biotechnology Letters 20(4), 411-415.

Tobert JA. 2003 - Lovastatin and beyond: the history of HMG-CoA reductase inhibitors. Nature Reviews 2, 517-526.

Vilches Ferrón MA, Casas López JL, Péerez Sánchez JA, Fernández Sevilla JM, Christi Y. 2005 Rapid screening of Aspergillus terreus mutants for overproduction of lovastatin. World Journal of Microbiology and Biotechnology 2, 123-125. 